\title{
Progression of cervical neoplasia in HIV- seropositive women with and without antiretroviral therapy in Johannesburg, South Africa
}

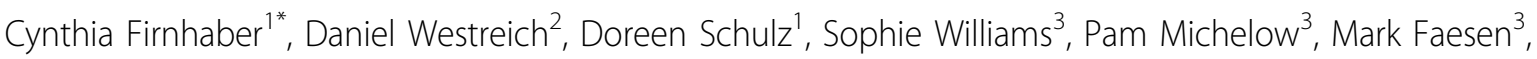 \\ Simon Levin ${ }^{3}$, Jennifer Smith²
}

From $12^{\text {th }}$ International Conference on Malignancies in AIDS and Other Acquired Immunodeficiencies (ICMAOI)

Bethesda, MD, USA. 26-27 April, 2010

\section{Background}

HIV-seropositive women have a higher risk of oncogenic HPV infection, cervical neoplasia, and cervical cancer than HIV-seronegative women. As HIV-seropositive women begin to live longer due to effective highly active antiretroviral therapy (HAART), their risk of developing cervical cancer may increase. Little data exist regarding the progression of cervical neoplasia in HIV seropositive women from sub-Saharan Africa.

\section{Methods}

A longitudinal observational study of 2,106 HIV-seropositive women was performed to determine progression rates of cytological outcomes in a government HIV clinic in Johannesburg, South Africa, stratified by use of HAART. The 2001 Bethesda grading system was to classify conventional Pap smear diagnoses. The effect of HAART use at initial visit on rate of progression of cervical neoplasia was determined using multivariate Poisson regression to obtain incidence rate ratios (IRRs) adjusted for age, CD4 count, history of STDs, use of hormonal contraception, parity, number of lifetime sex partners, and age at first sexual contact.

\section{Results}

The cohort comprised 741 HIV-seropositive women with at least two visits more than 6 months apart. Mean

\footnotetext{
*Correspondence: cindy.firnhaber@righttocare.org

'Department of Medicine, University of Witwatersrand, Johannesburg,

South Africa

Full list of author information is available at the end of the article
}

followup time among these women was 565 days (median 449 days; intraquartile range 382-698 days). Among women with a normal baseline Pap $(\mathrm{n}=326), 76(23 \%)$ progressed to LSIL or HSIL, at a rate of 16.0 (95\% CL $12.8,20.0)$ per 100 woman-years. Among women with LSIL at baseline Pap $(\mathrm{n}=275), 46(17 \%)$ progressed to HSIL at a rate of 10.8 (95\% CL 8.1, 14.4) per 100 womanyears. Of the remaining 140 women with HSIL at baseline Pap who not assessed treatment before repeat Pap smear, none progressed to cancer. In multivariate Poisson regression, women receiving HAART at baseline visit were less likely to progress than women not receiving HAART at baseline (IRR $=0.60,95 \%$ CL 0.41, 0.87). Results were similar regardless of baseline Pap result, and using multivariate Cox proportional hazards models (hazard ratio, 0.55, 95\% CL 0.38, 0.80). In addition, lower CD4 counts were associated with higher rates of cervical neoplasic progression, although results were imprecise.

\section{Conclusion}

This is one of the first reports of progression rates of cervical neoplasia among HIV-positive women. These rates among women from South Africa are concerning. There is an urgent need for broad-reaching screening/ treatment in Africa.

\section{Acknowledgements}

This article has been published as part of Infectious Agents and Cancer Volume 5 Supplement 1, 2010: Proceedings of the $12^{\text {th }}$ International Conference on Malignancies in AIDS and Other Acquired 
Immunodeficiencies (ICMAOI).The full contents of the supplement are available online at http://www.biomedcentral.com/1750-9378/5?issue=S1

\section{Author details}

'Department of Medicine, University of Witwatersrand, Johannesburg,

South Africa. ${ }^{2}$ Department of Epidemiology, University of North Carolina,

Raleigh, NC, USA. ${ }^{3}$ Right to Care, Johannesburg, South Africa.

Published: 11 October 2010

doi:10.1186/1750-9378-5-S1-A67

Cite this article as: Firnhaber et al:: Progression of cervical neoplasia in HIV-seropositive women with and without antiretroviral therapy in Johannesburg, South Africa. Infectious Agents and Cancer 2010 5(Suppl 1):A67.

Submit your next manuscript to BioMed Central and take full advantage of:

- Convenient online submission

- Thorough peer review

- No space constraints or color figure charges

- Immediate publication on acceptance

- Inclusion in PubMed, CAS, Scopus and Google Scholar

- Research which is freely available for redistribution

Submit your manuscript at www.biomedcentral.com/submit 